\title{
Lost in Translation or Just Too Pragmatic?
}

\section{Validation of the German Broader Autism Phenotype Questionnaire (BAPQ-G)}

\author{
Timo Lorenz@ and Mona Algner \\ Department of Psychology, Medical School Berlin, Germany
}

\begin{abstract}
The Broader Autism Phenotype Questionnaire (BAPQ) is a measure to assess a set of personality and language characteristics reflecting the phenotypic expression of autistic traits in neurotypically developing individuals. This paper aims to evaluate the newly developed German version of the BAPQ (BAPQ-G) in terms of its factorial validity. We performed confirmatory factor analyses and correlations with other measures of the broader autism phenotype on three German samples $\left(N_{1}=248, N_{2}=289, N_{3}=255\right)$. Associations with other constructs are in line with the assumptions, yet the anticipated factor structure of the BAPQ-G did not meet the cutoff criteria. These results are discussed along with recent findings regarding other cultural versions of the BAPQ.
\end{abstract}

Keywords: broader autism phenotype, autism, validation, confirmatory factor analysis, psychometrics

Autism spectrum condition (ASC) is characterized by difficulties in social communication and interaction as well as stereotyped, repetitive behaviors (American Psychiatric Association $[\mathrm{APA}], 2013)$. The autism spectrum varies between a lower-than-average IQ oftentimes nonverbal individuals, and so-called high-functioning individuals with an average to above-average IQ (Wing, 1997).

Twin data suggest a genetic liability for autism (Folstein \& Rutter, 1977), which can result in a milder form of autistic traits in neurotypical relatives of individuals on the autism spectrum (Ingersoll \& Wainer, 2014). These subclinical differences, referred to as the broader autism phenotype (BAP), are in their domains, similar to the diagnostic criteria of ASC, but differ in their quality and severity (Piven, 2001). The BAP comprises a group of social and communication skills and personality features frequently found in neurotypical relatives of individuals on the autism spectrum (Ingersoll \& Wainer, 2014). For example, parents of children on the spectrum report to be less attuned to solely social interactions and have fewer and lower quality friendships than control parents (Losh et al., 2008; Piven et al., 1997). Furthermore, Maxwell et al. (2013) found that parental BAP predicts child functioning in ASC. While the BAP is more frequently found in first-degree relatives of individuals on the autism spectrum (e.g., Sung et al., 2005), it also seems to exist within the general population (e.g., Baron-Cohen et al., 2001; Constantino \& Todd, 2005), thus supporting the idea of an autism spectrum. These findings emphasize the importance of more research on the BAP, both in relatives of autistic individuals and in the typically developing population, which might aid in gaining a better understanding of the developmental trajectories of autistic tendencies (Godoy-Giménez et al., 2018; Landry \& Chouinard, 2016).

\section{BAP Domains}

While there are specific clinical diagnostic criteria for ASC (APA, 2013), this is not the case for the BAP, since it is a subclinical phenomenon. This lack of criteria has made comparisons across studies difficult, but scholars have described core features of the BAP (e.g., Losh et al., 2011), suggesting that ASC and the BAP share the same areas of difficulty, but differ in their degree of severity and quality (Wainer et al., 2011). These areas will be highlighted with regard to how they relate between ASC and the BAP.

\section{Social Behavior and Personality}

Difficulties regarding social behaviors such as anxiousness, difficulty maintaining close friendships, or difficulty 
adjusting to change are considered core features of ASC (APA, 2013) and can be indicative of the BAP as well (Ingersoll \& Wainer, 2014). Relatives of autistic individuals have been found more likely to display such traits, among them shyness, rigidity, anxious or eccentric behaviors, and aloofness or unresponsiveness (Murphy et al., 2000; Pickles et al., 2000). Nonautistic siblings of individuals on the autism spectrum have shown early developmental differences in terms of social behavior such as responding to one's name (Nadig et al., 2007) or social smiling (Toth et al., 2007). Jobe and Williams White (2007) found a relation between social functioning and BAP in a nonclinical sample. Individuals with higher BAP levels and a desire for social interaction were reporting more loneliness and had fewer and shorter friendships (Bauminger \& Kasari, 2000). Pollmann et al. (2010) suggest that high levels of BAP could influence romantic relationships in both quality and satisfaction.

Wainer et al. (2011) assume that these respective individuals may strive to engage with others but fail due to the lack of socially expected skills, which leads to social rejection. The authors propose that social difficulties of individuals with high levels of BAP could be related to both the ability to communicate, that is, pragmatic language and said difficulties, and the actual interest in interaction, that is, aloofness.

\section{Rigid Behaviors and Interests}

Restricted, repetitive, and stereotyped behavioral patterns and interests are seen as characteristic for ASC but can also be found in siblings and parents of individuals on the autism spectrum (Christensen et al., 2010). Individuals with high levels of autistic traits display a preference for activities involving systematizing as well as a tendency to analyze, understand, or construct rule-based systems (Baron-Cohen, 2002; Ingersoll \& Wainer, 2014). These behavioral and interest-related characteristics can be expressed more mildly in family members of individuals on the autism spectrum (Baron-Cohen, 2002).

\section{Pragmatic Language and Communication}

ASC is also characterized by difficulties in language and communication skills. Whereas evidence on structural language difficulties is mixed at best (Ingersoll \& Wainer, 2014), there is a larger, more consistent body of research on pragmatic language, that is, difficulties with the social use of language. Pragmatics refer to such skills as taking turns in conversations or sticking to a conversational topic, but also relate to nonverbal elements such as gestures, eye contact, vocal prosody, or facial expressions (Ingersoll \& Wainer, 2014). In self-reports, difficulties with pragmatics appear to be more common in siblings and adult family members of individuals on the autism spectrum compared to control parents (e.g., Ruser et al., 2007). Ingersoll and Wainer (2014) state that research on pragmatic language difficulties in nonclinical samples is limited, yet findings do suggest a correlation between pragmatic language problems and the BAP. For example, there has been evidence of early language delay in younger siblings of individuals on the autism spectrum (Constantino et al., 2010) and less pronounced social communication, for example, gestures, pointing to objects, and social smiling (Toth et al., 2007).

\section{Assessing the BAP}

Previously, various methods were employed to assess characteristics of the BAP in parents of individuals on the autism spectrum, for example, family history interviews (Piven et al., 1997), as well as instruments originally meant to assess autistic traits, for example, the Social Responsiveness Scale (SRS; Constantino, 2002) and the Autism Quotient (AQ; Baron-Cohen et al., 2001). As these instruments are often used to assess the BAP without being developed for that purpose, we will give a brief overview to facilitate a better understanding of similarities and differences between them before proceeding to the Broader Autism Phenotype Questionnaire (BAPQ; Hurley et al., 2007), which was specifically developed to assess the BAP.

\section{Social Responsiveness Scale}

The SRS is a parent/teacher questionnaire aimed at distinguishing children on the spectrum from those with typical development based on the child's ability to engage in reciprocal social interactions (Constantino et al., 2003). The SRS has five theoretically defined subscales including reciprocal social behavior, communication, and stereotyped behaviors and interests, with symptoms ranging from what is referred to as normal to autistic behavior (Hurley et al., 2007). Originally developed to be used in children, an adapted version for adults has since been published (adult version of the SRS [SRS-A]; Bölte, 2012). Used for the assessment of the BAP, studies have shown that siblings of children on the autism spectrum score higher on the SRS than siblings of neurotypical children (Constantino et al., 2007). Subthreshold autistic traits assessed by the SRS appear to be continuously distributed in the general population (Constantino \& Todd, 2005). 


\section{Autism Quotient}

The AQ (Baron-Cohen et al., 2001) assesses core features of ASC on five subscales. It is a self-assessment questionnaire identifying the degree to which an adult of normal intelligence exhibits autistic traits (Wheelwright et al., 2010). Several scholars have employed the AQ to assess the BAP, although it was never intended to be used as a BAP measure. Wheelwright et al. (2010), for example, found that parents of children on the autism spectrum score higher on four out of five subscales of the AQ compared to parents without children on the autism spectrum. Bishop et al. (2004) reported similar findings with higher scores of parents of children on the autism spectrum on two out of five subscales, social skills and communication, concluding that the $\mathrm{AQ}$ is sensitive to the BAP when attention is being restricted to these two areas.

\section{Broader Autism Phenotype Questionnaire}

The SRS is mainly used to assess social behavior, while the AQ assesses the three defining constructs of autism (that is, social skills, attention to detail, and communication) as well as attention switching and imagination. In contrast to the AQ and the SRS, the BAPQ was specifically designed to identify the BAP in nonautistic relatives of individuals on the autism spectrum, assessing the theoretically defined core features of the BAP on three subscales: aloof personality, rigid personality, and pragmatic language problems (Hurley et al., 2007). The BAPQ was developed to assess these three components because they correspond to the conceptually defining areas of autism (social, stereotyped-repetitive, and communication difficulties), suggesting a strong theoretical relevance (Hurley et al., 2007). Furthermore, Piven et al. (1997) showed that these areas of difficulties occur more frequently in parents of autistic individuals than other BAP features, such as untactful behavior. The main purpose of the BAPQ is to provide an efficient, valid, and reliable screening tool to detect individuals exhibiting the subclinical characteristics of the BAP that are below the clinical threshold targeted by the standard ASC assessment (Hurley et al., 2007).

\section{Aloof Personality}

Defined as a lack of interest in or enjoyment of social interaction (Hurley et al., 2007). Wainer et al. (2011) found aloofness to be correlated with specific personal interests: There was a negative relation with preferences for attending parties, social networking and music, while being positively associated with a preference for being alone.

\section{Rigid Personality}

Defined as little interest in change or difficulty adjusting to change (Hurley et al., 2007). Previous studies have found rigidity to be associated with lower agreeableness, higher neuroticism, and lower extraversion due to cognitive and behavioral inflexibility (Ingersoll \& Wainer, 2014), as well as with a negative association with attending social events such as parties (Wainer et al., 2011).

\section{Pragmatic Language Problems}

Defined as deficits in the social aspects of language resulting in difficulties communicating effectively or in holding a fluid, reciprocal conversation (Hurley et al., 2007). Wainer et al. (2011) suggest that while persons scoring high on pragmatic language may not have a distinct aversion toward social relationships, these relationships may be made difficult due to the persons' language abilities.

\section{Psychometric Properties of the BAPQ}

In previous studies, the BAPQ has adequate internal consistency for both the total score $(\alpha>.90)$ and each of its subscales $(\alpha>.70)$. However, in recent validation studies using confirmatory factor analyses (CFAs), the BAPQ exhibited a questionable factor structure across cultures (e.g., Broderick et al., 2015; Godoy-Giménez et al., 2018). For example, in the CFA of the Spanish version of the BAPQ Godoy-Giménez et al. (2018) reported a root mean square error of approximation (RMSEA) of .07, a comparative fit index (CFI) of .74, and moderate to low factor loadings (aloof personality: range $=[.31, .80]$, rigid personality: range $=[.29, .72]$, pragmatic language: range $=[.03, .73]$ ). Specifically, items of the pragmatic language factor seemed to be the main source of global misfit. Broderick et al. (2015) performed exploratory analyses to identify alternative models of the BAPQ after finding limited goodness-of-fit, testing a four-factor structure which included an anxiety factor that was part of the original BAPQ conceptualization (Piven et al., 1997). In the end, the authors rejected their adapted version because it did not yield evidence of model fit and returned to the originally proposed three-factor structure. However, Broderick et al. (2015) did not retest their measurement models with a second sample.

In the evaluation of psychometric properties of the Brazilian translation of the BAPQ Prata et al. (2019) performed an exploratory factor analysis (EFA), a comparison between clinical and nonclinical groups, and determined internal consistency. In their EFA, a threecomponent structure emerged with factors that are in line with the original conceptualization of the BAPQ by Hurley et al. (2007). However, they also found that five items of the pragmatic language factor loaded higher on 
aloof personality than on their theoretically ascribed factor, indicating again that the pragmatic language factor might not be well-designed. Finally, Sharma and Bhushan (2018) performed EFAs to validate the Hindi version of the BAPQ. They reported a loading pattern that indicated a different factor structure and suggested an adapted 18item version of the questionnaire. Their suggested version only included three items on the pragmatic language factor (factor loadings range $=.30-.38$ ) and four items on the rigid factor (factor loadings range $=.40-.58$ ), thus further questioning the factorial validity of the BAPQ.

\section{Aim of This Study}

In light of these findings and the fact that the original BAPQ was never validated by means of a CFA, the purpose of this study is to validate the newly translated German version of the BAPQ (BAPQ-G) in a German sample. Ingersoll et al. (2011) have found strong positive correlations between different BAP instruments ranging from $r=.55$ to .66 . Hence, a strong positive association is expected between the BAPQ- $G$ and the full-length $A Q$ and the AQ-10 (Allison et al., 2012) and the SRS-A. We further expect a strong positive correlation between the BAPQ-G and the Social Phobia Inventory (SPIN; Stangier \& Steffens, 2002), and the revised Obsessive Compulsive Inventory (OCI-R; Gönner et al., 2007) and the items of the socially avoidant subscale of the Inventory of Interpersonal Problems (Horowitz et al., 2016).

Among all three subscales of the BAPQ-G, there should be positive correlations with the Big Five Inventory (BFI; Schupp \& Gerlitz, 2014) subscale neuroticism, and negative correlations with agreeableness and extraversion, as well as openness (Wainer et al., 2011). As for conscientiousness, negative correlations are expected with pragmatic language due to more interpersonal problems and aloof personality because of social detachment, as well as negative correlations with rigid personality based on findings of negative correlations between conscientiousness and high AQ scores by Wakabayashi et al. (2006). Furthermore, we aim to investigate the theoretical threefactor structure of the BAPQ in a German sample.

\section{Method}

\section{Participants and Procedure}

We included three data sets with a total of 792 participants $\left(N_{1}=248, N_{2}=289, N_{3}=255\right)$. Eight individuals were removed from the total sample due to implausible response behavior with no variance in their answers. Table 1 includes descriptive statistics of all three data sets.

Most of the participants (89.76\%) were either employees $\left(n_{1}=136, n_{2}=107, n_{3}=83\right)$ or students $\left(n_{1}=84, n_{2}=151\right.$, $\left.n_{3}=150\right)$. The study was conducted in German and participation was voluntary; hence, no incentives were supplied. Participants were recruited on several online social media platforms. The study was approved by the ethics commission of the Medical School Berlin (MSB2019/08).

\section{Instruments}

\section{Demographics}

Participants were asked to state their age, gender, highest level of completed education, employment status, and sector of employment encoded with the classification of occupations 2010 (Bundesagentur für Arbeit, 2011).

\section{BAPQ-G}

On a rating scale ranging from $1=$ very rarely to $6=$ very often, participants rated 36 statements (see Electronic Supplementary Material 1 [ESM 1]). The new German version of this scale was developed using a standard translation-back-translation procedure with several native speakers familiar with cultural nuances (Guillemin et al., 1993). We used the BAPQ-G in all three data sets.

\section{$A Q$}

The AQ-10 (Allison et al., 2012) is the short version of the AQ-50 (Baron-Cohen et al., 2001). Each item is rated on a rating scale ranging from $1=$ definitely agree to $4=$ definitely disagree. The AQ-10 was used in Data set 1, and the AQ-50 in Data set 2.

\section{SRS-A}

The SRS-A (Bölte, 2012) was used to assess autistic traits. Its 65 items are rated on scale from $1=$ not true to $4=$ almost always true. For the purpose of this study, wording in the instructions was changed, adapting the SRS-A to a selfreport format. The SRS-A was used in Data set 1.

\section{Big Five}

The BFI-S (Schupp \& Gerlitz, 2014) with 15 items reflecting the personality traits openness, conscientiousness, agreeableness, extraversion, and neuroticism was assessed on a rating scale from $1=$ does not apply to me at all to $7=$ applies to me perfectly. The BFI-S was used in Data set 2.

\section{Social Phobia Inventory}

We used the SPIN (Stangier \& Steffens, 2002) in Data set 2 with 17 items surveying the characteristic domains of social anxiety. On a rating scale from $1=$ not at all to 
Table 1. Descriptive statistics of all three data sets

\begin{tabular}{llllll}
\hline & $M_{\text {age }}(S D)$ & $N_{\text {female }}$ & $N_{\text {male }}$ & $N_{\text {nonbinary }}$ & $N_{\text {diagnosis }}$ \\
\hline Data set 1 & $35.74(3.90)$ & $178(71.77 \%)$ & $68(27.42 \%)$ & $2(0.81 \%)$ & $5(2.02 \%)$ \\
Data set 2 & $30.54(10.83)$ & $216(74.74 \%)$ & $69(23.87 \%)$ & $4(1.40 \%)$ & $3(1.04 \%)$ \\
Data set 3 & $29.76(11.03)$ & $176(69.02 \%)$ & $76(29.80 \%)$ & $3(1.18 \%)$ & $0(0.00 \%)$ \\
\hline
\end{tabular}

5 = extremely, participants rated the degree to which specific problems had affected them over the past week.

\section{Revised Obsessive Compulsive Inventory}

The OCI-R (Gönner et al., 2007) with 18 items was employed in Data set 2. Participants stated on a rating scale from $1=$ not at all to $5=$ very much the degree to which behaviors or experiences affected them in the past.

\section{Inventory of Interpersonal Problems (IIP-D)}

Participants rated the four items of the socially avoidant subscale of the Inventory of Interpersonal Problems (IIP-D; Horowitz et al., 2016) on a rating scale from $1=$ does not apply at all to 5 = fully applies. We used the IIP-D in Data set 2 .

\section{ASC Diagnosis}

All participants were asked to indicate whether they have ever received an official ASC diagnosis.

\section{Statistical Analyses}

Data analysis was performed using the package lavaan (version 0.6-7; Rosseel, 2012) of the statistical software R (version 3.6.1; R Core Team, 2020). We evaluated the factorial validity of the BAPQ-G (for the model visualization refer to ESM 2), with a confirmatory factor analysis, using the proposed criteria by Hu and Bentler (1999). To augment the overly conservative $\chi^{2}$ test, those criteria include a standardized root mean square residual (SRMR) $\leq .08$ in combination with at least one of the following fit indices: a RMSEA $\leq .06$, a lower bound of the $90 \%$ CI of the RMSEA $\leq .06$, a comparative fit index $(\mathrm{CFI}) \geq .95$, or a Tucker-Lewis index $\geq .95$. Furthermore, we also report individual cutoff values tailored to the empirical data using the R package ezCutoffs (Schmalbach et al., 2019). Traditional fit measure cutoffs, although having almost reached canonical status, should be regarded with caution. $\mathrm{Hu}$ and Bentler (1998) themselves warned that cutoffs resulting from simulation studies are only appropriate under the investigated conditions, and thus should neither be interpreted as rigid, nor be overgeneralized (McNeish \& Wolf, 2020). Several methodological studies have scrutinized the use of fixed cutoff values and found that, given other conditions, that is, other empirical data, cutoff values might fluctuate, for example, with changes in data and model characteristics, degrees of freedom (e.g., Kenny et al., 2015), or factor loading and factor reliability (e.g., Heene et al., 2011). This, in turn, makes it harder to identify cutoff values appropriate for the data set at hand. Contemporary approaches generate dynamic fit index cutoffs by simulating data sets with similar characteristics to the data set under consideration (McNeish \& Wolf, 2020). In other words, they mimic the process used by Hu and Bentler (1999), with parameters corresponding to the empirical model, thus generating individual cutoff values, similar to the traditional ones that are applicable for the empirical model (McNeish $\&$ Wolf, 2020). Besides the global fit, we also analyzed local model fit by means of modification indices to guide future research to improve the questionnaire.

Estimators of CFA models, such as the maximum likelihood (ML), usually assume observed variables to be continuous and multivariate normally distributed. In the behavioral sciences, where it is common to use questionnaires with few answer categories, this assumption often does not hold. Consequently, robust estimators (e.g., maximum likelihood robust; MLR) have been developed to deal with violations of the normal distribution. Simulation studies showed that ML-based estimators tend to produce biased results with regard to factor loadings and $S E$ s when non-normality was severe (e.g., Beauducel \& Herzberg, 2006). Diagonally weighted least squares (WLSMVs) on the other hand is an appropriate estimator when the sample is relatively small and the normality assumption is violated (Li, 2016). Thus, in this study, we used WLSMV to estimate the CFA models.

To test convergent and divergent validity of the BAPQ$G$, bivariate correlation analyses were conducted with other BAP measures and personality scales. We report McDonald's $\omega_{\mathrm{t}}$ as an estimate of the total reliability of a test since it is the appropriate measure for tests that do not meet the assumption of tau-equivalence (Revelle \& Condon, 2019). To help facilitate comparison with earlier studies, we also report Cronbach's $\alpha$. Analysis of the data set revealed seven missing values $(=.03 \%)$. We used listwise deletion to deal with the missing data.

We fixed the scales of the latent variables by fixing factor loadings of the first indicator of a latent variable to 1 . All the correlations between factors were freed, and all the cross-loadings were fixed to zero. If the current BAPQ-G model fits the data reasonably well, we would consider 
Table 2. Model fits (CFAa) and individual cutoff values of the BAPQ-G

\begin{tabular}{|c|c|c|c|c|c|c|c|c|c|}
\hline & $N$ factors & $\chi^{2}$ & $d f$ & $p$ & SRMR & TLI & $\mathrm{CFI}$ & RMSEA & RMSEA $90 \% \mathrm{Cl}$ \\
\hline Data set 1 & 3 & $1,450.43$ & 591 & $<.001$ & .088 & .839 & .849 & .077 & {$[.072, .082]$} \\
\hline Data set 2 & 3 & 1769.42 & 591 & $<.001$ & .093 & .855 & .864 & .083 & {$[.079, .088]$} \\
\hline Data set 3 & 3 & $1,334.12$ & 591 & $<.001$ & .082 & .870 & .878 & .070 & {$[.065, .075]$} \\
\hline \multicolumn{10}{|c|}{ Individual cutoff values } \\
\hline Data set 1 & 3 & 719.83 & 591 & & .052 & .949 & .953 & .029 & \\
\hline Data set 2 & 3 & 712.11 & 591 & & .047 & .962 & .965 & .026 & \\
\hline Data set 3 & 3 & 685.36 & 591 & & .050 & .961 & .963 & .025 & \\
\hline
\end{tabular}

retaining it. In case of a bad model fit, we analyzed local fit to provide further directions for the improvement of the scale. In both cases, we aim to replicate our previous findings in Data set 2 and 3.

\section{Results}

To investigate the three-factor structure of the BAPQ a CFA model was fitted in each data set. Table 2 shows the results of the CFA (for item statistics refer to ESM 3). With reference to the fit criteria of Hu and Bentler (1999), the BAPQ-G displayed acceptable global model fit in Data set 1 and 3, with only SRMR and RMSEA marginally reaching the cutoff criteria. In Data set 2, the global model fit was poor. Individual cutoff values, as proposed by McNeish and Wolf (2020), also in Table 2, indicate that model fit in all data sets was not acceptable. As expected, the indicators showed significant positive factor loadings, with standardized coefficients for aloof personality ranging from .55 to .82 in Data set 1 (Data set 2: range $=[.49, .82]$, Data set 3: range $=[.57$, $.80]$ ), pragmatic language ranging from .31 to .76 (Data set 2: range $=[.17, .86]$, Data set 3: range $=[.22, .80])$, and rigid personality ranging from .37 to .80 (Data set 2: range $=[.36$, $.78]$, Data set 3: range $=[.27, .80])$. For factor loadings and SEs, refer to Table 3.

Modification indices in all three samples were highest for the same items of the pragmatic language subscale, especially those related to potential error covariances - pragmatic language item 9 ("I can tell when someone is not interested in what I am saying") and 12 ("I can tell when it is time to change topics in conversation"). Furthermore, several items of the pragmatic and the aloof personality subscale exhibited potential cross-loadings, especially item 5 of the pragmatic language subscale ("I feel disconnected or 'out of sync' in conversations with others") loaded on the aloof personality factor in all three data sets (modification index range $=[43.26$, 125.71]).
Table 4 presents descriptive statistics and reliability measures. All external instruments, except the AQ-10 and the BFI facets conscientiousness and agreeableness, show acceptable scores for McDonald's $\omega_{\mathrm{t}}$ and Cronbach's $\alpha$. In all three data sets, McDonald's $\omega_{t}$ was $>.90$ for the total scores of the BAPQ-G. The aloof personality and rigid personality subscales displayed acceptable reliability $\left(\omega_{t}\right.$ ranging from .84-.91), while McDonald's $\omega_{\mathrm{t}}$ for pragmatic language ranged from .73 to .78 . Cronbach's $\alpha$ showed similar coefficients.

Bivariate correlation analyses were conducted to test convergent validity of each of the measures (Table 5 and Table 6). Each of the instruments used to assess the BAP (i.e., BAPQ AQ-10, AQ-50, and SRS-A) correlated moderately to strongly with the other three. The BAPQ-G correlated negatively with all personality facets of the BFI except neuroticism (Table 7). The three BAPQ-G subscales correlated with each other at a statistically significant level $(p<.01)$ between $r=.35$ and .59 . Overall, these results are in line with previous research (e.g., Ingersoll et al., 2011) and suggest convergent validity, although an acceptable model fit was not obtained in either data set.

\section{Discussion}

The aim of this study was to validate the BAPQ-G regarding its factorial structure and association with other measures of the BAP. The present data demonstrate that the BAPQ-G does not fit its proposed theoretical model. These findings are in line with previous studies examining the BAPQ regarding its factorial validity (e.g., Broderick et al., 2015; Godoy-Giménez et al., 2018). Closer examination on item level suggested the pragmatic language subscale to be the main cause of misfit in all three samples. One reason might be content-overlapping (i.e., items on the pragmatic language scale being more related to the 
Table 3. Factor loadings and standard errors BAPQ-G in all three data sets

\begin{tabular}{|c|c|c|c|}
\hline Item (abbreviation) & Factor loading & $\begin{array}{l}\text { Standardized } \\
\text { factor loading }\end{array}$ & SE \\
\hline \multicolumn{4}{|l|}{ Factor aloof personality } \\
\hline I like being around other people. (a1r) & 1.00/1.00/1.00 & $.77 / .77 / .75$ & - \\
\hline I would rather talk to people to get information than to socialize. (a2) & $.90 / .98 / .53$ & $.69 / .75 / .64$ & 0.05/0.05/0.05 \\
\hline I enjoy being in social situations. (a3r) & 1.04/1.02/1.02 & $.80 / .78 / .76$ & $0.04 / 0.04 / 0.05$ \\
\hline People find it easy to approach me. (a4r) & $.82 / .65 / .87$ & $.63 / .50 / .65$ & $0.06 / 0.06 / 0.06$ \\
\hline I look forward to situations where I can meet new people. (a5r) & 1.06/1.06/1.07 & $.82 / .82 / .80$ & $0.04 / 0.04 / 0.05$ \\
\hline When I make conversation, it is just to be polite. (a6) & $.76 / .89 / .93$ & $.58 / .68 / .70$ & $0.07 / 0.05 / 0.06$ \\
\hline I am good at making small talk. (a7r) & $.97 / .90 / .95$ & $.75 / .68 / .71$ & 0.05/0.05/0.05 \\
\hline I feel like I am really connecting with other people. (a8r) & $.73 / .98 / .83$ & $.56 / .75 / .62$ & $0.06 / 0.04 / 0.06$ \\
\hline Conversation bores me. (a9) & $.71 / .81 / .92$ & $.55 / .62 / .69$ & $0.07 / 0.05 / 0.05$ \\
\hline I am warm and friendly in my interactions with others. (a10r) & $.73 / .77 / .76$ & $.56 / .59 / .57$ & $0.06 / 0.06 / 0.06$ \\
\hline I prefer to be alone rather than with others. (a11) & $.91 / 1.03 / .93$ & $.70 / .79 / .70$ & $0.04 / 0.04 / 0.06$ \\
\hline I enjoy chatting with people. (a12r) & 1.03/1.05/1.07 & $.79 / .81 / .80$ & $0.04 / 0.04 / 0.05$ \\
\hline \multicolumn{4}{|l|}{ Factor pragmatic language } \\
\hline I find it hard to get my words out smoothly. (pl1) & 1.00/1.00/1.00 & $.57 / .55 / .28$ & - \\
\hline It's hard for me to avoid getting sidetracked in conversation. (pl2) & $.63 / .72 / 1.46$ & $.36 / .40 / .40$ & $0.11 / 0.12 / 0.41$ \\
\hline I am "in-tune" with the other person during conversation. (pl3r) & $.80 / 1.05 / 2.34$ & $.46 / .58 / .65$ & $0.14 / 0.14 / 0.57$ \\
\hline My voice has a flat or monotone sound to it. (pl4) & 1.07/1.16/1.93 & $.61 / .64 / .54$ & $0.12 / 0.13 / 0.50$ \\
\hline I feel disconnected or "out of sync" in conversations with others. (pl5) & $1.33 / 1.55 / 2.90$ & $.76 / .86 / .80$ & $0.15 / 0.16 / 0.71$ \\
\hline $\begin{array}{l}\text { People ask me to repeat things I've said because they don't } \\
\text { understand. (pl6) }\end{array}$ & $.91 / .96 / 1.67$ & $.52 / .53 / .46$ & $0.13 / 0.12 / 0.42$ \\
\hline I have been told that I talk too much about certain topics. (pl7) & $.59 / .37 / .78$ & $.34 / .21 / .22$ & $0.13 / 0.12 / 0.30$ \\
\hline I speak too loudly or softly. (pl8) & $.70 / .52 / 1.50$ & $.40 / .29 / .41$ & $0.12 / 0.11 / 0.41$ \\
\hline I can tell when someone is not interested in what I am saying. (pl9r) & $.54 / .31 / 1.18$ & $.31 / .17 / .33$ & $0.13 / 0.11 / 0.41$ \\
\hline I leave long pauses in conversation. (pl10) & $.89 / 1.12 / 2.20$ & $.51 / .66 / .61$ & $0.14 / 0.12 / 0.53$ \\
\hline I lose track of my original point when talking to people. (pl11) & $1.03 / 1.27 / 1.65$ & $.59 / .71 / .46$ & $0.13 / 0.14 / 0.38$ \\
\hline I can tell when it is time to change topics in conversation. (pl12r) & $.71 / .69 / 1.79$ & $.40 / .38 / .50$ & $0.13 / 0.11 / 0.45$ \\
\hline \multicolumn{4}{|l|}{ Factor rigid personality } \\
\hline I am comfortable with unexpected changes in plans. ( $r 1 \mathrm{r})$ & 1.00/1.00/1.00 & $.37 / .52 / .53$ & - \\
\hline People have to talk me into trying something new. (r2) & $2.06 / 1.47 / 1.51$ & $.77 / .77 / .80$ & $0.32 / 0.13 / 0.15$ \\
\hline I have to warm myself up to the idea of visiting an unfamiliar place. (r3) & 1.92/1.34/1.33 & $.71 / .70 / .70$ & $0.29 / 0.12 / 0.13$ \\
\hline I feel a strong need for sameness from day to day. (r4) & 1.81/1.30/1.19 & $.67 / .68 / .63$ & $0.28 / 0.12 / 0.14$ \\
\hline I am flexible about how things should be done. ( $r 5 r)$ & 1.87/1.19/1.22 & $.69 / .63 / .65$ & $0.26 / 0.11 / 0.14$ \\
\hline I look forward to trying new things. (r6r) & $2.16 / 1.49 / 1.46$ & $.80 / .78 / .77$ & $0.31 / 0.12 / 0.14$ \\
\hline I have a hard time dealing with changes in my routine. $(r 7)$ & 2.01/1.37/1.38 & $.75 / .72 / .73$ & $0.28 / 0.12 / 0.13$ \\
\hline I act very set in my ways. (r8) & 1.79/1.38/1.09 & $.67 / .72 / .58$ & $0.26 / 0.13 / 0.11$ \\
\hline People get frustrated by my unwillingness to bend. (r9) & $1.09 / .83 / .51$ & $.41 / .44 / .27$ & $0.22 / 0.12 / 0.13$ \\
\hline I alter my daily routine by trying something different. (r10r) & 1.46/1.16/1.03 & $.54 / .61 / .55$ & $0.21 / 0.12 / 0.13$ \\
\hline I like to closely follow a routine while working. (r11) & $1.21 / .69 / .56$ & $.45 / .36 / .30$ & $0.20 / 0.11 / 0.11$ \\
\hline $\begin{array}{l}\text { I keep doing things the way I know, even if another way might be } \\
\text { better. (r12) }\end{array}$ & $1.40 / .89 / .96$ & $.52 / .46 / .51$ & $0.22 / 0.11 / 0.12$ \\
\hline
\end{tabular}

Note. BAPQ = Broader Autism Phenotype Questionnaire, BAPQ-G = German version of the BAPQ. Item abbreviations in brackets. Suffix r refers to reverse-scored items.

aloof personality factor). For example, item 5 of the pragmatic language factor ("I feel disconnected or 'out of sync' in conversations with others") might be too similar in meaning to items of the aloof personality subscale (e.g., "I feel like I am really connecting with other people"; item 8 [reverse scored]). Furthermore, the error covariance 
Table 4. Descriptive statistics and reliability coefficients

\begin{tabular}{|c|c|c|c|c|}
\hline & $\alpha\left(\omega_{t}\right)$ & $M(S D)$ & Skew & Kurtosis \\
\hline$A Q 50$ & $.82(.84)$ & $2.15(0.34)$ & 0.49 & 0.87 \\
\hline$A Q-10$ & $.62(.69)$ & $2.10(0.34)$ & 0.54 & 0.52 \\
\hline IIP-D & $.83(.83)$ & $2.50(0.28)$ & 0.43 & -0.71 \\
\hline $\mathrm{OCl}-\mathrm{R}$ & $.90(.91)$ & $1.90(0.31)$ & 0.94 & 0.61 \\
\hline SRS-A & $.96(.96)$ & $1.59(0.37)$ & 1.58 & 2.73 \\
\hline SPIN & $.93(.93)$ & $2.32(0.36)$ & 0.68 & -0.12 \\
\hline Openness & $.71(.74)$ & $5.03(1.20)$ & -0.54 & -0.01 \\
\hline Conscientiousness & $.64(.68)$ & $5.35(0.90)$ & -0.43 & 0.15 \\
\hline Extraversion & $.84(.85)$ & $4.72(1.30)$ & -0.21 & -0.72 \\
\hline Agreeableness & $.56(.58)$ & $5.16(0.95)$ & -0.41 & -0.19 \\
\hline Neuroticism & $.73(.75)$ & $4.37(1.26)$ & -0.04 & -0.77 \\
\hline \multicolumn{5}{|l|}{ BAPQ-G } \\
\hline Data set 1 & $.91(.93)$ & $2.69(0.55)$ & 0.58 & 0.68 \\
\hline Data set 2 & $.92(.93)$ & $2.80(0.62)$ & 0.40 & -0.29 \\
\hline Data set 3 & $.91(.92)$ & $2.69(0.55)$ & 0.47 & 0.64 \\
\hline \multicolumn{5}{|l|}{ Aloof personality } \\
\hline Data set 1 & $.89(.90)$ & $2.85(0.80)$ & 0.49 & 0.11 \\
\hline Data set 2 & $.91(.91)$ & $3.00(0.90)$ & 0.26 & -0.47 \\
\hline Data set 3 & $.90(.90)$ & $2.83(0.81)$ & 0.24 & -0.21 \\
\hline \multicolumn{5}{|l|}{ Pragmatic language } \\
\hline Data set 1 & $.76(.77)$ & $2.42(0.55)$ & 0.79 & 0.86 \\
\hline Data set 2 & .78 (.78) & $2.52(0.62)$ & 0.67 & 0.32 \\
\hline Data set 3 & $.74(.73)$ & $2.46(0.54)$ & 0.44 & 0.52 \\
\hline \multicolumn{5}{|l|}{ Rigid personality } \\
\hline Data set 1 & $.86(.86)$ & $2.81(0.68)$ & 0.39 & 0.46 \\
\hline Data set 2 & $.86(.87)$ & $2.89(0.75)$ & 0.48 & 0.23 \\
\hline Data set 3 & $.83(.84)$ & $2.79(0.66)$ & 0.43 & 0.30 \\
\hline
\end{tabular}

between items of the pragmatic subscale suggests the potential existence of another factor.

Hurley et al. (2007) suggest that the items of the BAPQ have face validity and report that the data show internal consistency of the BAPQ subscales. Apparently, the original BAPQ was never tested with confirmatory factor analyses. The assumed factorial structure of the model was only tested with an exploratory factor analysis (Ingersoll et al., 2011) and a principal component analysis (Sasson et al., 2013). CFA structures are more restrictive than EFA structures due to the fact that cross-loadings in CFA are traditionally constrained to zero while they are freely estimated in EFA. This leads to exactly the problem encountered in the analyses in the current study: instruments that have been well established by means of EFA research are not supported by CFAs (Marsh et al., 2014).

The results of the correlational analyses correspond with previous studies (Hollander et al., 2003; Jacob et al., 2009; Wainer et al., 2011). The results in the current study suggest a high association between the SPIN and the BAPQ-G total and moderate positive correlations between the SPIN and all the BAPQ-G subscales. Similar to previous studies (Murphy et al., 2000; Wakabayashi et al., 2006), we found higher levels of BAP came with lower scores in extraversion, conscientiousness, and agreeableness. All assumptions regarding correlations between all BAPQ-G subscales with the BFI personality inventory subscales were met. It is noteworthy that the correlation of the aloof personality subscale with extraversion was higher than the correlation between aloof personality and the BAPQ-G subscales. This might indicate that the aloof personality items assess extraversion to some degree (e.g., item 3, "I like being in social situations"). Furthermore, the three subscales of the BAPQ-G exhibited relatively low correlations with each other $(r=.35-.59)$, suggesting that focusing on an overall score, as was intended by Hurley et al. (2007), is at least questionable. It seems more plausible that the BAPQ-G assesses three domains, rather than a higher order construct. With the SRS-A, the AQ-50, and the AQ-10, we included instruments originally developed to assess ASC, which were previously used in studies to assess the BAP. The correlation coefficients of the three instruments with the BAPQ-G were very different, especially that the BAPQ-G and the AQ-10 showed only a moderate correlation. Furthermore, the SRSA correlated higher with the total BAPQ-G scale than with

Table 5. Intercorrelations in data set 1

\begin{tabular}{|c|c|c|c|c|c|c|}
\hline & BAPQ-G & Aloof & Rigidity & Pragmatic language & $A Q-10$ & SRS-A \\
\hline$B A P Q-G$ & 1 & & & & & \\
\hline Aloof & $.84^{\star \star \star}$ & 1 & & & & \\
\hline Rigidity & $.84^{\star \star *}$ & $.54^{\star \star \star}$ & 1 & & & \\
\hline Pragmatic language & $.75^{\star \star \star}$ & $.43^{\star \star \star}$ & $.52 * \star \star$ & 1 & & \\
\hline$A Q-10$ & $.58 * \star \star$ & $.42^{\star \star \star}$ & $.52^{\star \star \star}$ & $.48 * \star \star$ & 1 & \\
\hline SRS-A & $.75^{\star \star \star}$ & $.58 * \star \star$ & 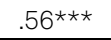 & 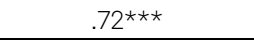 & $.64 \star \star \star$ & 1 \\
\hline
\end{tabular}

Note. AQ-10 = Autism Spectrum Quotient (short form), BAPQ = Broader Autism Phenotype Questionnaire, BAPQ-G = BAPQ-G = BAPQ German Version, SRS$A=$ Social Responsiveness Scale for Adults. ${ }^{* \star *} p<.001 ; N=248$. 
Table 6. Intercorrelations data set 2

\begin{tabular}{|c|c|c|c|c|c|c|c|c|}
\hline & $\mathrm{BAPQ}$ & Aloof & Rigidity & Pragmatic language & $A Q$ & SPIN & $\mathrm{OCl}$ & $\| P$ \\
\hline BAPQ & 1 & & & & & & & \\
\hline Aloof & $.89 * \star \star$ & 1 & & & & & & \\
\hline Rigidity & 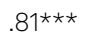 & $.59 * \star \star$ & 1 & & & & & \\
\hline Pragmatic language & $.72^{\star \star \star}$ & $.50 * \star \star$ & 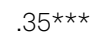 & 1 & & & & \\
\hline$A Q$ & $.80 * \star \star$ & $.75^{\star \star \star}$ & $.61^{\star \star \star}$ & $.56^{\star \star \star}$ & 1 & & & \\
\hline SPIN & $.67 * \star \star$ & $.57^{\star \star \star}$ & $.57^{\star \star \star}$ & $.48^{\star \star \star}$ & $.59 * \star \star$ & 1 & & \\
\hline $\mathrm{OCl}$ & $.40 \star \star \star$ & $.23 * \star \star$ & $.41^{\star \star \star}$ & $.35^{\star \star \star}$ & $.44^{\star \star \star}$ & 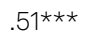 & 1 & \\
\hline$\| P$ & $.70 * \star \star$ & $.66^{\star \star *}$ & $.55^{\star \star \star}$ & $.46^{\star \star \star}$ & 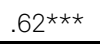 & $.73 * \star \star$ & $.39 * * *$ & 1 \\
\hline
\end{tabular}

Note. $\mathrm{AQ}=$ Autism Spectrum Quotient, $\mathrm{BAPQ}=$ Broader Autism Phenotype Questionnaire, BFI = Big Five Inventory, IIP = Inventory of Interpersonal Problems, $\mathrm{OCl}=$ Obsessive-Compulsive Inventory-Revised, SPIN = Social Phobia Inventory. ${ }^{\star \star} p<.01,{ }^{* \star *} p<.001 ; N=289$.

its subscales with the exception of the pragmatic language subscale. This is not surprising since the SRS-A assesses reciprocal social behavior as well as communication. However, these results suggest that the instruments used in the past to assess the BAP cannot be used interchangeably.

\section{Similar Findings and Future Directions}

Recent studies involving the BAPQ have found similar results regarding the instrument's model fit across cultures. For instance, a study by Godoy-Giménez et al. (2018) suggests that pragmatic language as a subscale was a problematic point in their CFA of a Spanish version of the BAPQ. Losh and Piven (2007) report aloofness and rigidity to have been the most valid and reliable scales to distinguish relatives of individuals on the autism spectrum from controls in past studies, which puts a spotlight on the more recent findings regarding the pragmatic language subscale.

Broderick et al. (2015) found limited goodness-of-fit for the original three-factor structure of the BAPQ as well as their adapted four-factor version that included an anxiety factor. Finally, Sharma and Bhushan (2018) performed EFAs to validate the Hindi version of the BAPQ. They reported a different factor structure and suggested a brief, adapted version of the questionnaire.

These findings suggest problems with the operationalization of the BAP, especially the pragmatic language factor. It is possible that this factor is more heterogeneous than previous ideas would suggest and in fact needs a representation with more than just one factor. Future research should focus on the conceptualization of the construct. Another possible approach would be to revise the pragmatic language factor with new items. Additionally, in the original paper on the BAPQ Hurley et al. (2007) reported that the subscales form an overall score. It thus would be possible to include a theoretical general factor into the estimation of the CFA model. It is important to keep in mind that this addition would be theoretically plausible when calculating an overall score, but would not change the model fit unless additional constraints are added as the three correlations would be replaced by three factor loadings. However, with regard to the relatively low intercorrelations of the three BAPQ-G subfacets in the current samples, we did not include a general factor. Future instruments to assess the BAP should aim for a stricter approach to develop a valid instrument. Loevinger (1957) proposed a theory-driven approach to scale

Table 7. Intercorrelations for BAPQ and BFI subscales in data set 2

\begin{tabular}{|c|c|c|c|c|c|c|c|c|c|}
\hline & $\mathrm{BAPQ}$ & Aloof & Rigidity & Pragmatic language & 0 & C & $E$ & A & $\mathrm{N}$ \\
\hline $\mathrm{BAPQ}$ & 1 & & & & & & & & \\
\hline Aloof & $.89 * \star \star$ & 1 & & & & & & & \\
\hline Rigidity & 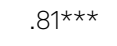 & $.59 * \star \star$ & 1 & & & & & & \\
\hline Pragmatic language & 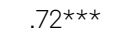 & 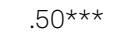 & 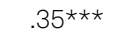 & 1 & & & & & \\
\hline 0 & $-.28 * \star \star$ & $-.25 \star \star \star$ & $-.28 * \star \star$ & $-.13^{\star}$ & 1 & & & & \\
\hline C & $-.28 \star \star \star$ & $-.18 \star \star$ & $-.21 \star \star \star$ & $-.32^{\star \star \star}$ & $.13^{\star}$ & 1 & & & \\
\hline$E$ & $-.69 * \star \star$ & $-.76^{\star \star \star}$ & $-.45^{\star \star \star}$ & $-.42^{\star \star \star}$ & $.23^{\star \star \star}$ & .10 & 1 & & \\
\hline A & $-.30 \star \star \star$ & $-.23^{\star \star \star}$ & $-.26 \star \star \star$ & $-.24^{\star \star \star}$ & .09 & $.12^{\star}$ & .00 & 1 & \\
\hline$N$ & $.39 * \star \star$ & $.24^{\star \star \star}$ & $.46^{\star \star \star}$ & 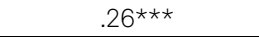 & -.06 & -.10 & $-.20 \star \star \star$ & -.08 & 1 \\
\hline
\end{tabular}

Note. BAPQ = Broader Autism Phenotype Questionnaire, BFI = Big Five Inventory, $\mathrm{O}=$ Openness, $\mathrm{C}=$ Conscientiousness, $\mathrm{E}=$ Extraversion, $\mathrm{A}=\mathrm{Agreeableness,}$ $N=$ Neuroticism. ${ }^{*} p<.05, * * p<.01,{ }^{* *} p<.001 ; N=255$. 
construction involving three aspects of construct validity: substantive validity, structural validity, and external validity. Unfortunately, the majority of research conducted in the behavioral and psychological sciences is focused on external validity without providing evidence for substantive and structural validity, respectively (Flake et al., 2017). This leads not only to the problems encountered in the present study but also poses questions regarding the validity of the results found in the external phase. Applied to the BAPQ it seems necessary to begin with a sound conceptualization and generation of new items to better reflect the concept and consequently use CFAs to validate its factor structure. Furthermore, we suggest that scholars emphasize the replication of possible factor structures with a CFA approach during the validation process using a split data set or even more than one data set.

Additionally, more research is needed to investigate the assumption that the BAPQ is more suitable to assess the BAP than standard autism assessment. Empirical evidence for this claim is inconsistent, and we encourage scholars to further explore the relation between BAP and ASC, especially regarding the sensitivity and validity of existing and future assessment tools.

\section{Limitations}

Some limitations concerning the generalizability of the results should be considered. First, due to using a nonprobability sample, generalizability is questionable. When interpreting the results, it should be kept in mind that the samples predominantly self-identified as female with a higher educational background.

Second, since the BAPQ-G is a self-report questionnaire and there is no comparison of the results of the BAPQ-G to direct clinical assessment such as a combination of data on a person's developmental history, family history of ASC, medical/genetic data, and standardized assessments of cognitive, behavioral, and language skills (Richdale \& Schreck, 2008), it is not possible to establish with certainty its ability to identify the BAP.

\section{Conclusion}

The BAPQ-G met the assumptions regarding the subscales' association with other constructs. The BAPQ-G subscales correlate positively with scales assessing related constructs, indicating convergent validity. Yet, the confirmatory factor analyses of the model did not provide acceptable model fit, suggesting that the assumed three- factor structure of the BAPQ-G appears inappropriate. Taking into account the aforementioned similar findings from different translations, the BAPQ may have to be reevaluated regarding the items of the pragmatic language factor or even the factor itself.

\section{Electronic Supplementary Material}

The electronic supplementary material is available with the online version of the article at doi: $10.1027 / 2698$ 1866/a000016.

ESM 1. The BAPQ-G.

ESM 2. Model for BAPQ-G

ESM 3. Item statistics for BAPQ-G

\section{References}

Allison, C., Auyeung, B., \& Baron-Cohen, S. (2012). Toward brief "red flags" for autism screening: The short autism spectrum quotient and the short quantitative checklist in 1,000 cases and 3,000 controls. Journal of the American Academy of Child \& Adolescent Psychiatry, 51(2), 202-212. https://doi.org/10.1016/j.jaac.2011.11.003 American Psychiatric Association. (2013). Diagnostic and statistical manual of mental disorders (5th ed.). https://doi.org/10.1176/ appi.books.9780890425596

Baron-Cohen, S. (2002). The extreme male brain theory of autism. Trends in Cognitive Sciences, 6(6), 248-254. https://doi.org/10. 1016/S1364-6613(02)01904-6

Baron-Cohen, S., Wheelwright, S., Skinner, R., Martin, J., \& Clubley, E. (2001). The autism-spectrum quotient (AQ): Evidence from asperger syndrome/high-functioning autism, males and females, scientists and mathematicians. Journal of Autism and Developmental Disorders, 31(1), 5-17. https://doi.org/10.1023/A:1005653411471

Bauminger, N., \& Kasari, C. (2000). Loneliness and friendship in high-functioning children with autism. Child Development, 71(2), 447-456. https://doi.org/10.1111/1467-8624.00156

Beauducel, A., \& Herzberg, P. Y. (2006). On the performance of maximum likelihood versus means and variance adjusted weighted least squares estimation in CFA. Structural Equation Modeling: A Multidisciplinary Journal, 13(2), 186-203. https://doi. org/10.1207/s15328007sem1302_2

Bishop, D. V. M., Maybery, M., Maley, A., Wong, D., Hill, W., \& Hallmayer, J. (2004). Using self-report to identify the broad phenotype in parents of children with autistic spectrum disorders: A study using the autism-spectrum quotient. Journal of Child Psychology and Psychiatry, 45(8), 1431-1436. https://doi. org/10.1111/j.1469-7610.2004.00325.x

Bölte, S. (2012). Brief report: The social responsiveness scale for adults (SRS-A): Initial results in a German cohort. Journal of Autism and Developmental Disorders, 42(9), 1998-1999. https:// doi.org/10.1007/s10803-011-1424-5

Broderick, N., Wade, J. L., Meyer, J. P., Hull, M., \& Reeve, R. E. (2015). Model invariance across genders of the broad autism phenotype questionnaire. Journal of Autism and Developmental Disorders, 45(10), 3133-3147. https://doi.org/10.1007/s10803-015-2472-z

Bundesagentur für Arbeit. (2011). Klassifikation der Berufe 2010. Bundesagentur für Arbeit. 
Christensen, L., Hutman, T., Rozga, A., Young, G. S., Ozonoff, S., Rogers, S. J., Baker, B., \& Sigman, M. (2010). Play and developmental outcomes in infant siblings of children with autism. Journal of Autism and Developmental Disorders, 40(8), 946-957. https://doi.org/10.1007/s10803-010-0941-y

Constantino, J. N. (2002). The social responsiveness scale [Measurement instrument]. Western Psychological Services.

Constantino, J. N., Davis, S. A., Todd, R. D., Schindler, M. K., Gross, M. M., Brophy, S. L., Metzger, L. M., Shoushtari, C. S., Splinter, R., \& Reich, W. (2003). Validation of a brief quantitative measure of autistic traits: Comparison of the social responsiveness scale with the autism diagnostic interview-revised. Journal of Autism and Developmental Disorders, 33(4), 427-433. https://doi.org/ 10.1023/A:1025014929212

Constantino, J. N., Lavesser, P. D., Zhang, Y., Abbacchi, A. M., Gray, T., \& Todd, R. D. (2007). Rapid quantitative assessment of autistic social impairment by classroom teachers. Journal of the American Academy of Child \& Adolescent Psychiatry, 46(12), 1668-1676. https://doi.org/10.1097/chi.0b013e318157cb23

Constantino, J. N., \& Todd, R. D. (2005). Intergenerational transmission of subthreshold autistic traits in the general population. Biological Psychiatry, 57(6), 655-660. https://doi.org/10.1016/j. biopsych.2004.12.014

Constantino, J. N., Zhang, Y., Frazier, T., Abbacchi, A. M., \& Law, P. (2010). Sibling recurrence and the genetic epidemiology of autism. The American Journal of Psychiatry, 167(11), 1349-1356. https://doi.org/10.1176/appi.ajp.2010.09101470

Flake, J. K., Pek, J., \& Hehman, E. (2017). Construct validation in social and personality research: Current practice and recommendations. Social Psychological and Personality Science, 8(4), 370-378. https://doi.org/10.1177/1948550617693063

Folstein, S., \& Rutter, M. (1977). Infantile autism: A genetic study of 21 twin pairs. Journal of Child Psychology and Psychiatry, 18(4), 297-321. https://doi.org/10.1111/j.1469-7610.1977.tb00443.x

Godoy-Giménez, M., González-Rodríguez, A., Cañadas, F., Estévez, A. F., \& Sayans-Jiménez, P. (2018). Psychometric properties of the Spanish version of the broad autism phenotype questionnaire: Strengths, weaknesses, and future improvements. Journal of Autism and Developmental Disorders, 48(3), 770-783. https://doi.org/10.1007/s10803-017-3438-0

Gönner, S., Leonhart, R., \& Ecker, W. (2007). Das Zwangsinventar OCl-R - Die deutsche Version des Obsessive-Compulsive Inventory-Revised. PPmP - Psychotherapie Psychosomatik Medizinische Psychologie, 57(09/10), 395-404. https://doi.org/ 10.1055/s-2007-970894

Guillemin, F., Bombardier, C., \& Beaton, D. (1993). Cross-cultural adaptation of health-related quality of life measures: Literature review and proposed guidelines. Journal of Clinical Epidemiology, 46(12), 1417-1432. https://doi.org/10.1016/0895-4356(93)90142-N

Heene, M., Hilbert, S., Draxler, C., Ziegler, M., \& Bühner, M. (2011). Masking misfit in confirmatory factor analysis by increasing unique variances: A cautionary note on the usefulness of cutoff values of fit indices. Psychological Methods, 16(3), 319-336. https://doi.org/10.1037/a0024917

Hollander, E., King, A., Delaney, K., Smith, C. J., \& Silverman, J. M. (2003). Obsessive-compulsive behaviors in parents of multiplex autism families. Psychiatry Research, 117(1), 11-16. https://doi. org/10.1016/S0165-1781(02)00304-9

Horowitz, L., Strauß, M., Thomas, A., \& Kordi, H. (2016). Inventar zur Erfassung interpersonaler Probleme - Deutsche Version [The inventory of interpersonal problems - German version]. 3. überarbeitete Auflage.

Hu, L.-t., \& Bentler, P. M. (1998). Fit indices in covariance structure modeling: Sensitivity to underparameterized model misspecification. Psychological Methods, 3(4), 424-453. https://doi. org/10.1037/1082-989X.3.4.424
Hu, L.-t., \& Bentler, P. M. (1999). Cutoff criteria for fit indexes in covariance structure analysis: Conventional criteria versus new alternatives. Structural Equation Modeling: A Multidisciplinary Journal, 6(1), 1-55. https://doi.org/10.1080/10705519909540118

Hurley, R. S. E., Losh, M., Parlier, M., Reznick, J. S., \& Piven, J. (2007). The broad autism phenotype questionnaire. Journal of Autism and Developmental Disorders, 37(9), 1679-1690. https:// doi.org/10.1007/s10803-006-0299-3

Ingersoll, B., Hopwood, C. J., Wainer, A., \& Brent Donnellan, M. (2011). A comparison of three self-report measures of the broader autism phenotype in a non-clinical sample. Journal of Autism and Developmental Disorders, 41(12), 1646-1657. https:// doi.org/10.1007/s10803-011-1192-2

Ingersoll, B., \& Wainer, A. (2014). The broader autism phenotype. In F. R. Volkmar, R. Paul, S. J. Rogers, \& K. A. Pelphrey (Eds.), Handbook of autism and pervasive developmental disorders: Diagnosis, development, and brain mechanisms (4th ed.). John Wiley \& Sons, Inc. https://doi.org/10.1002/9781118911389. hautc02

Jacob, S., Landeros-Weisenberger, A., \& Leckman, J. F. (2009) Autism spectrum and obsessive-compulsive disorders: $\mathrm{OC}$ behaviors, phenotypes and genetics. Autism Research, 2(6), 293-311. https://doi.org/10.1002/aur.108

Jobe, L. E., \& Williams White, S. (2007). Loneliness, social relationships, and a broader autism phenotype in college students. Personality and Individual Differences, 42(8), 1479-1489. https:// doi.org/10.1016/j.paid.2006.10.021

Kenny, D. A., Kaniskan, B., \& McCoach, D. B. (2015). The performance of RMSEA in models with small degrees of freedom. Sociological Methods \& Research, 44(3), 486-507. https://doi. org/10.1177/0049124114543236

Landry, O., \& Chouinard, P. A. (2016). Why we should study the broader autism phenotype in typically developing populations. Journal of Cognition and Development, 17(4), 584-595. https:// doi.org/10.1080/15248372.2016.1200046

Li, C.-H. (2016). Confirmatory factor analysis with ordinal data: Comparing robust maximum likelihood and diagonally weighted least squares. Behavior Research Methods, 48(3), 936-949. https://doi.org/10.3758/s13428-015-0619-7

Loevinger, J. (1957). Objective tests as instruments of psychological theory. Psychological Reports, 3(3), 635-694. https://doi. org/10.2466/pr0.1957.3.3.635

Lorenz, T., \& Algner, M. (2020). Lost in translation or just too pragmatic? Validation of the German Broader Autism Phenotype Questionnaire (BAPQ-G) [Data sets]. https://doi.org/psycharchives. org/handle/20.500.12034/3945

Lorenz, T., \& Algner, M. (2021). Lost in translation or just too pragmatic? Validation of the German Broader Autism Phenotype Questionnaire (BAPQ-G). [Code]. https://doi.org/psycharchives.org/handle/20.500. $12034 / 3946.3$

Losh, M., Adolphs, R., \& Piven, J. (2011). The broad autism phenotype. In G. Dawson, D. Amaral, \& D. Geschwind (Eds.), Autism spectrum disorders (pp. 457-476). Oxford University Press. https://doi.org/10.1093/med/9780195371826.003.0031

Losh, M., Childress, D., Lam, K., \& Piven, J. (2008). Defining key features of the broad autism phenotype: A comparison across parents of multiple- and single-incidence autism families. American Journal of Medical Genetics Part B: Neuropsychiatric Genetics, 147B(4), 424-433. https://doi.org/b.30612

Losh, M., \& Piven, J. (2007). Social-cognition and the broad autism phenotype: Identifying genetically meaningful phenotypes. Journal of Child Psychology and Psychiatry, 48(1), 105-112. https://doi.org/10.1111/j.1469-7610.2006.01594.x

Marsh, H. W., Morin, A. J. S., Parker, P. D., \& Kaur, G. (2014). Exploratory structural equation modeling: An integration of the best features of exploratory and confirmatory factor analysis. 
Annual Review of Clinical Psychology, 10(1), 85-110. https://doi. org/10.1146/annurev-clinpsy-032813-153700

Maxwell, C. R., Parish-Morris, J., Hsin, O., Bush, J. C., \& Schultz, R. T. (2013). The broad autism phenotype predicts child functioning in autism spectrum disorders. Journal of Neurodevelopmental Disorders, 5(1), 25. https://doi.org/10.1186/1866-1955-5-25

McNeish, D., \& Wolf, M. G. (2020, July 7). Dynamic fit index cutoffs for confirmatory factor analysis models. https://doi.org/10. 31234/osf.io/v8yru

Murphy, M., Bolton, P. F., Pickles, A., Fombonne, E., Piven, J., \& Rutter, M. (2000). Personality traits of the relatives of autistic probands. Psychological Medicine, 30(6), 1411-1424. https://doi. org/10.1017/S0033291799002949

Nadig, A. S., Ozonoff, S., Young, G. S., Rozga, A., Sigman, M., \& Rogers, S. J. (2007). A prospective study of response to name in infants at risk for autism. Archives of Pediatrics \& Adolescent Medicine, 161(4), 378. https://doi.org/10.1001/archpedi.161.4.378

Pickles, A., Starr, E., Kazak, S., Bolton, P., Papanikolaou, K., Bailey, A., Goodman, R., \& Rutter, M. (2000). Variable expression of the autism broader phenotype: Findings from extended pedigrees. Journal of Child Psychology and Psychiatry, 41(4), 491-502. https://doi.org/10.1111/1469-7610.00634

Piven, J. (2001). The broad autism phenotype: A complementary strategy for molecular genetic studies of autism. American Journal of Medical Genetics, 105(1), 34-35. https://doi.org/10. 1002/1096-8628(20010108)105:1<34::AID-AJMG1052>3.0.C0;2-D

Piven, J., Palmer, P., Landa, R., Santangelo, S., Jacobi, D., \& Childress, D. (1997). Personality and language characteristics in parents from multiple-incidence autism families. American Journal of Medical Genetics, 74(4), 398-411. https://doi.org/10. 1002/(SICI)1096-8628(19970725)74:4<398::AID-AJMG11>3.0.CO;210. 1002/(sici)1096-8628(19970725)74:4<398::aid-ajmg11>3.0.co;2-d.-D

Pollmann, M. M. H., Finkenauer, C., \& Begeer, S. (2010). Mediators of the link between autistic traits and relationship satisfaction in a non-clinical sample. Journal of Autism and Developmental Disorders, 40(4), 470-478. https://doi.org/10.1007/s10803-009-0888-z

Prata, L. D. L., Camargos Junior, W., Teodoro, M. L. M., \& Rocha, F. L. (2019). Qualidades psicométricas da versão brasileira da escala broad autism phenotype questionnaire (BAPQ-Br). Contextos Clínicos, 12(1), 186-203. https://doi.org/10.4013/ctc.2019.121.08

R Core Team. (2020). R: A language and environment for statistical computing [Software]. http://www.R-project.org/

Revelle, W., \& Condon, D. M. (2019). Reliability from $\alpha$ to $\omega$ : A tutorial. Psychological Assessment, 31(12), 1395-1411. https://doi. org/10.1037/pas0000754

Richdale, A. L., \& Schreck, K. A. (2008). Assessment and intervention in autism. In J. L. Matson (Ed.), Clinical assessment and intervention for autism spectrum disorders (pp. 3-32). Elsevier. https://doi.org/10.1016/B978-012373606-2.50003-6

Rosseel, Y. (2012). lavaan: An R package for structural equation modeling. Journal of Statistical Software, 48(2), 1-36. https:// doi.org/10.18637/jss.v048.i02

Ruser, T. F., Arin, D., Dowd, M., Putnam, S., Winklosky, B., RosenSheidley, B., Piven, J., Tomblin, B., Tager-Flusberg, H., \& Folstein S. (2007). Communicative competence in parents of children with autism and parents of children with specific language impairment. Journal of Autism and Developmental Disorders, 37(7), 1323-1336. https://doi.org/10.1007/s10803-006-0274-z

Sasson, N. J., Lam, K. S. L., Childress, D., Parlier, M., Daniels, J. L., \& Piven, J. (2013). The broad autism phenotype questionnaire: Prevalence and diagnostic classification: The BAPQ in a large community-based sample. Autism Research, 6(2), 134-143. https://doi.org/10.1002/aur.1272

Schmalbach, B., Irmer, J. P., \& Schultze, M. (2019). ezCutoffs: Fit measure cutoffs in SEM (Version 1.0.1).

Schupp, J., \& Gerlitz, J.-Y. (2014). Big Five Inventory-SOEP (BFI-S). https://doi.org/10.6102/zis54

Sharma, U., \& Bhushan, B. (2018). The Hindi adaptation and standardization of BAPQ: A brief tool for assessing broad autism phenotype. Asian Journal of Psychiatry, 38, 16-19. https://doi. org/10.1016/j.ajp.2018.10.008

Stangier, U., \& Steffens, M. (2002). Social phobia inventory (SPIN) - Deutsche Fassung. Psychologisches Institut der Universität Frankfurt am Main.

Sung, Y. J., Dawson, G., Munson, J., Estes, A., Schellenberg, G. D., \& Wijsman, E. M. (2005). Genetic investigation of quantitative traits related to autism: Use of multivariate polygenic models with ascertainment adjustment. The American Journal of Human Genetics, 76(1), 68-81. https://doi.org/10.1086/426951

Toth, K., Dawson, G., Meltzoff, A. N., Greenson, J., \& Fein, D. (2007). Early social, imitation, play, and language abilities of young nonautistic siblings of children with autism. Journal of Autism and Developmental Disorders, 37(1), 145-157. https://doi.org/10. 1007/s10803-006-0336-2

Wainer, A. L., Ingersoll, B. R., \& Hopwood, C. J. (2011). The structure and nature of the broader autism phenotype in a non-clinical sample. Journal of Psychopathology and Behavioral Assessment, 33(4), 459-469. https://doi.org/10.1007/s10862-011-9259-0

Wakabayashi, A., Baron-Cohen, S., \& Wheelwright, S. (2006). Are autistic traits an independent personality dimension? A study of the autism-spectrum quotient (AQ) and the NEO-PI-R. Personality and Individual Differences, 41(5), 873-883. https://doi. org/10.1016/j.paid.2006.04.003

Wheelwright, S., Auyeung, B., Allison, C., \& Baron-Cohen, S. (2010). Defining the broader, medium and narrow autism phenotype among parents using the autism spectrum quotient (AQ). Molecular Autism, 1(1), 10. https://doi.org/10.1186/ 2040-2392-1-10

Wing, L. (1997). The autistic spectrum. The Lancet, 350(9093), 1761-1766. https://doi.org/10.1016/S0140-6736(97)09218-0

\section{History}

Received November 19, 2020

Revision received September 28, 2021

Accepted September 28, 2021

Published online December 6, 2021

\section{Open Data}

The data sets are available at https://www.psycharchives.org/ handle/20.500.12034/3945 (Lorenz \& Algner, 2020).

The code is available at https://www.psycharchives.org/handle/ 20.500.12034/3946.3 (Lorenz \& Algner, 2021).

\section{ORCID}

Timo Lorenz

(D) https://orcid.org/0000-0002-3830-489X

\section{Timo Lorenz}

Rüdesheimer Str. 50

14197 Berlin

Germany

timo.lorenz@medicalschool-berlin.de 